\title{
Notas sobre la Filosofía de las Upanishads.
}

\section{PTIMOLOGIA. SIGNIFICADO.}

El términó Upanishad (I) es de etimología y sentido oscuros. La interpretación más aceptada es la considera que la palabra viene de la raíz sad sentarse, estar sentado, con los prefijos upa y ui y significaría la enseñanza esotérica de caracter nistico-filosófico trasnitida al discípulo respetuoso sentado cerca y frente del maestro. También se ha proptiesto (Oldenberg) el significado de "adoración a 'Brahman" basánclose en un sentido muly corriente de sad con el prefijo upa. Los comentadores hinclus por su lado aceptan la etimología que hace derivar el térnino de ttin verbo sad, quemar, con lo rue se expresa el valor salutario de estas doctrinas.

\section{NUMERO, FECHA, PRINCIPALRS.}

El número de las Upanishads es bastante grande: la $M u k-$ tika Upanishad da una lista de Io8 pero actualmente se posee de ellos mas de 200 , no estando conformes los autores

(1) Citnmos las Uprnislatals a base de las siguientes ediciones:

(a) Trihadarangaka, Kathnka, Iea, Kena, Mundaka ed. Poley, Bonn 1S44 (texto sunsctito).

(b) Chandogya ed. Sennrt, París 1930 (texto sanserito y tradueción fran(esa).

(c) Parmahamsa, Atma, Alnritabindu, Tajabindu, Sarva, Aruneyi, Kaivalya ed. Swami Vireswarazanda, Mayavati 1928 (toxto samserito). 
acerca de su número. Estas divergencias se explican por d hecho de no ser los Upanishads un género literario bien determinado y puciendo todo escrito místico recibir ese nombre, unido ésto a la circunstancia de que nunca dejaron de escribirse.

La fecha de composición de estos textos abarca varios siglos, siendo incierta para cada tno de ellos; algrunos son anteriores al „Budismo, pudiendo los mas antiguos remontarse hasta 700 antes de Cristo y otros fueron redactados ya cu época mahomética. Las principales Upanishads son las siguientes según la clasificación mas generalizada:

r) en prosa y estilo arcaico: Brihadaranyaka, Chandogya, Taittiriya, Aitareya, Kausitaki y parte de la Kena;

2) casi enteramente en yerso: Kathaka, Ica, Cvetacvatara, Mundaka, Mahanarayana y parte del Kena; dukya;

3) en prosa casi clásica: Pracna, Maitrayaniya, Man-

4) de inspiración sectaria: Atmabodha, Paramahamsa, etc. que consagran gran parte de su texto a la glorificación de divinidades determinadas, en especial: Visnú y Krisna y dan un lugar importante a la devocions (Bhakti).

\section{ORIGEN.}

Se ha afirmado (Deussen, Hertel y sobre todo Garbe: Beitrage zur indischen Kulturgeschichte, (Berlín I903, I p. I sg.) que las doctrinas de las Upanishads tuvieron su origen en la casta de los gutereros exclusivamente. Su principal argumento consiste en una serie de textos upanishadicos (Brihadaranyaka II, 4; VI, 2; Chandogya $5,2-24 ; \mathrm{I}, 8$ y 9 ; 3 ; etc.) en que aparecen Ksatriyas instruyendo a Brahmathes y en algunos de los cuales hay evidentes indirectas control la capacidad de los sacerdotes y alusiones a los guterreros co- 
mo creadores de las nuevas ideas. $Y$ Garbe dice: "El hecho que en escritos tan brahamánicos, en obras que son consideradas en la India con razón cono columnas maestras del Brahmanismo aparezcan tales narraciones nos habla en un lenguaje que no admite interpretaciones. Nos muestra que los redactores ( I ) de las antiguas Upanishads ni pensaron o no osaron encubrir la filiación aun notoria en su tiempo y presentar la ensefianza monjstica de Brahman-A tman como utha herencia de su clase". Garbe por lo demás acepta que los brahmanes se apropiaron desptés de estas enseñanzas y las convirtieron en ortodoxas. Esta teoria del origen Ksatriya de las doctrinas Upanishadicas ha sido atacada por Oldenbcrg, Dahlmaun, Oltremare, Keith (The religion and Philosophy of the Veda and Upanishads, If p. $489 \mathrm{sg}$. Cambridge, Mass. 1925) etc.; pero nos parece que sus argumentos no bastan para descartarla. Está demás poner de manifiesto la importancia del problenta, ya que en él se discute el mérito de la creación de la filosofia mas profunda y característica de la India.

\section{INSPIRACION GENERALD CARACTER IIISTCO}

Unánimenente se admite que en las Upanishads tencmos tuna nueva etapa de la evolución religiosa de la india.

Segun Masson Oursel (L' Inde antique et la civilisation indienne, París I933. p. I.57) esą nueva etapa tenciria un sentido intelectualista: "momento decisivo en la evolución religiosa; a la práctica de los ritos se sobrepone la pretensión ce comprender las condiciones de la existencia; el sacrificio verdadero y mas eficaz consiste en conocer pues es por medio de la inteligencia mas que por medio de las fórmulas que tmo elimina el mal como error. Jñana (ei conocimiento) tien-

(1) entiéndase: brajımánicos. 
de a tomar el lugar de Yajña (cl sacrificio)". Fero nos parece que estc cambio es cn otro scntidio, en un scntido sentimentalista de efusión mística y de religiosidad profuncla. El tono general de las Upanishads nos lo indica: no nos da en efecto una exposición sistemática y lógica de la doctrina o doctrinas que contienen, las verdades a que llegan mas que el producto de una investigación métodica y de una demostración ordenada lo son de la intuición poderosa clel viclente, del poeta, del nístico, líricas efusiones de misticismo, sentimentales inspiraciones metafísicas, en un lenguaje en que los términos no poseen un valor exacto y bien determinado. Además todas las Upanishads están de acuerdo al hablar del Ser Supremo de que este es algo absolutamente heterogéneo, algo que está "allende de la voz y la mente" y declaran que el intelecto es incapaz de llegar a él; y no es por lo tanto por medio de la razon que puede tener lugar la iluminación y la unión mística de que hablan. (cf. los textos citados al tratar de esta característica del Ser Suprenio). Por lo tanto el término Jñana no representa una función mental, discursiva, sino una captación intuitiva e integral de la Realidad Suprema y aun mas la realización efectiva de esa realiclad. Finalmente el amálgamiento en forma tan completa de las doctrimas upanishádicas con las creencias de las religiones de Visnú, Krisna, Rama, religiones de amor y de ternura, amalgamiento que se revela en la Bhagavad Gita y en otros textos no habría podido tener lugar si la inspiración no fuese icléntica en ambos: sentimiento y emoción. Que no es la inteligencia sino la intuición, que no es tna facultad del individuo sino sı mas propio "yo", quien capta lo absoluto, también lo deducimos de la disciplina a que debe someterse él que quiere llegar a la visión suprena, disciplina que tiene por objeto hacerle encontrar su propia personalidad, centralizarlo en su yo efectivo y no aguzar su inteligencia y desarrollar su pe- 
ricia en los métodos de pensar. La característica de esta disciplina es el ser negativo, toda ella tiende a purificar al hombre y su fin es la Katharsis absoluta. El vidente debe matar en si toda su vida sicológica, sentimientos, fantasías, sobre todo, todo deseo y aun la actividad intelectual de su espíritu que de una manera u otra lo ponen en contacto con el mundo exterior y con todo aquello que no es él mismo. (Heiler, Die Mystik in den Upanishadden, Leipzig I92.5 p. I2-I4).

Maurice Boucher en su estudio sobre la filosofía de Keyserling (París I927 p.5 s sg.), resumiendo las ideas de éste, alude a un rasgo esencial del espíritu hindú en oposición con el espíritu occidental. Sus palabras corroboran la interpretación que damos. "Los hindús están persuadidos que el conomiento del Ser (Brahmavidya), el único conocimiento que les parezca deseable, no puede ser adquirido por el pensamiento discursivo, pues éste no se mueve sino. en su esfera propia y por definición se encuentra incapaz de depasarla. Es tan poco apta a captar el conocimiento metáfísico como los sentidos. El conocimiento metafísico, en efecto, solo puede ser alcanzado gracias a una trasposición de la conciencia.

Los métodos son completamente incomparables. El occidente reflexiona, experimenta, critica. El hindú practica la disciplina del Yoga. Su objeto es traspasar los límites que Kant asigna a toda experiencia posible, transformando el organismo de su pensamiento. El europec progresa de noción cn noción, induce, deduce, distingue, integra. El hindú avanza de estado en estado. El tuno asciende siempre mas lejos en el mundo de las abstracciones, el otro modifica sin reposo la forma de su conciencia... Los hindús ellos también hablan de lo abstracto. Pero mientras que esta noción designa para nosotros un nivel de abstracción, ella expresa para ellos un estado vivido. No hay que ver una identidad ni aun una similidad donde no hay sino inconmensurab!es". Queremos tam- 
bién recordar aquí la interpretación cịte daba de los Upanishads Dvijendranath Tagora (hermano del poeta) : "He probado, he experimentado en mí mismo muchas de las verdades reveladas por los antiguos profetas... Nuestra filosofía india se resuelve en una práctica, en una experiencia de vida, adquiere valor en el momento en que pasa del campo de la abstracción al de la realización. En esto se aventaja de la filosofía del Occidente, la cual no llega jamás a conclusiones positivas, no se vuelve jamás religión (Formichi, India e indiani, Milán I929, P. I5I).

Al lado del elemento místico, es evidente e innegable la existencia de un elemento intelectualista y escolístico, y de un elemento mágico, de antigua historia en la India. Pero no son estos dos elementos, los característicos de los Upanishads.

Las causas que dieron origen a la nueva etapa que representan las Upanishac's fueron sin duda variadas.

Ante todo, como ha ocurrido en toda religión, no es de extrañar que en ciertos sectores de la sociedad brahmánica se sintiese en un momento dado que las creencias tradicionales demasiado impregnadas de racionalismo y haciendo caso omiso de la csentimentalidar eraneinsuficientes para satisfacer las necesidades de religiosidad profunda del hombre $y$ de ahí la necesidad de enfrentarles y remplazarlas por otras que respondiesen mejor a este sentimiento del espíritu humano. También se debe tomar en cuenta las influencias de los cultos de divinidades extrañas al Brahmanismo y de las sectas de Sofistas, Materialistas, Yogins. (cf. Masson Oursel, "Esquisse d'une histoire de la philosophie indienne. Paris 1923, p. 45-5). No dehemos tampoco descartar a priori el aporte que puedan tener los cultos de los aborígenes, si no como modelos que imitaron los arios, a lo menos como fermento en sus especulaciones. 


\section{CARACTER RPVOLUCIONARIO.}

Presupuesto esencial de las doctrinas upanishádicas es un cierto desprestigio de las creencias tradicionales. Aunque las Upanishads no rompen de modo abierto y violento con la tradición, dejan sin embargo traslucir claramente que sus doctrinas nada tienen que ver con las creencias brahmánicas y que el Saber que ellas preconizan es una forma de sabe: superior al enseñado por brahmanes. En el inicio de la sexta lectura de la Chandogya, Chvetaketu Artuleya después de haber concluido su noviciado regresa donde su padre, orgulloso de su fresco saber; su padre le pregunta si ha aprendido aquello "por medio de lo cual lo no-oido deviene oido, lo no-pensado deviene pensado, lo no-conocido deviene conocido"; el hijo declara que sus venerables macstros por ignorar-lo sin duda no se lo han enseñado y su padre debe instruirto en la doctrina suprema del Atman y su identidad con el Ser Suprenno, fundamento y explicación de todo. Por otro lado la Mundaka Upanishad declara que hay dos saberes: uno inferior que comprencle los Xedas, stis Comentarios y Exégcsis etc. y otro stperior por medio de lo cual "se llega a aquello Inalterable".

Pero mas importante a este respecto es el hecho quequitando algunos raros pasajes, parásitos o sobrevivencias, según justa expresión de Oltremare-las Upanishads no conceden ningun valor ni a los actos rituales ni a las prácticas ascéticas, y mas bien las consicleran como lazos que encaclenan al circtilo cerrado de las reencarnaciones al igual que cualquier acto de la vida. Según ellas es locura creer en su eficacia para llegar a la verdadera y rea felicidad. (cf. Chandogya Upanishad 5,24; 8, I,6; Mundaka Upanishad I,2; Brihadaranyaka Upanishad $3,8,10$ ).

Por este aspecto por decir asi revolucionario las Upanis- 
hads se relacionan con el Budismo y el Djainaismo apareciendo los tres como reacciones frente a las creencias religiosas tradicionales que comenzaban a revelarse insuficientes para llenar la vida espiritual.

\section{CARACTER ESOTERICO.}

Para terminar de dar una idea general de las Upanishads antes de abordar la exposición de sus doctrinas hay que recalcar el carácter esotérico que ellas mismas se prestan. Contienen enseñanzas que el depositar:o debe trasmitir al alumno solo después de muchos años de prueba y estudio (Chandogya Upanishad VIII, 7-I2,) que debe darse en lugar desierto y sin testigos (Brihadaranyaka Upanishad III, 2, I3), y después de muchos ruegos; mas aun el maestro debe escoger cuidadosamente al discípulo a quien va a trasmitir sus conocimientos (Chandogya Upanishad 3, I I, 5; Maitreyani Upanishad 6,29) y en algunos lutgares el término Upanishad tiene el valor de doctrina secreta.

\section{PUNTO DE vista ADOPTADO.}

En la exposición de las doctrinas Upanishádicas seguiremos la interpretación mas generalizada y aceptada y la que desarrollada e integrada constituye la doctrina ce la escuela clásica y ortodoxa del Vedanta. Pero esto no cebe bacernos olvidar que al lado de la interpretación monista del Vedanta existen interpretaciones enteramente opuestas como la dualista de Madhva (cf. Betty Heimann, Madhava's Kommentar zur Kathaka-Upanishad, Leipzig I922).

La misma variedad de puntos de vista se encuentra en el detalle, como en la doctrina de la unión mística. "La vagedad de las doctrinas de las Upanishads prodtijo el desarrollo de diferentes teorías a partir de los mismos textos. 
Algunos budistas interpretan la idea Upanishádica como que es un aniquilamiento íntegro (entire loss), algunos vedantistas como la auto-inmersión del alma individual en lo supremo. Otros sostienen que es una existencia eterna, absoluta, en el pensamiento amor y disfrute de lo supremo y no un aniquilamiento". (Radhakrishnan, Indian Philosophy, I pp. 24I-242 London 1923-I927). Por otro lado hemos acentuado el lado místico de las Upanishads por creer que una interpretación en ese sentido está más cerca de la verdad que una interpretación estrictamente filosófica.

\section{DOCTRINAS DE LAS UPANISHADS. BRAHMAN.}

La identidad del Ser Supremo (Brahman) con el alma individual (Atman) constituye el tema central de estos textos. Analizaremos por separado cada tuno de los términos de esta ecuación.

La existencia de Brahman no necesita pruebas a los ojos de los autores upanishádicos. Estos se hallan ocupados en describirlo sin sentir jamás la necesidad de dar argumentos en favor de su existencia. Débemos yer en esto una consecuencia de la dependencia de las Upanishads y de sus autores con la literatura tradicional de los Brahmanes: la importancia de la noción de Brahman en aquellos textos, el lugar central que ocupaba ya antes de las Upanishads en la especulación hindú y el continuo uso que de ella se hace, había acostumbrado a los espíritus a dar por sentada y fuera de duda la existencia del objeto que constituía su contenido. Por otro lado, dado el carácter místico y experiencial de las doctrinas de los textos que comentamos, hay que tener en cuenta que para sus autores no era necesario una demostración de la existencia de un Ser con quien ellos místicamente habían entrado en contacto y de cuya existrncia estaban plenamente seguros por conocimiento directo. 


\section{HETEROGENEIDAD DE BRAHMAN.}

El rasgo de Brahman que primero llama la atención es que es algo que ni el intelecto ni los senticlos logran abarcar o percibir, algo que trasciende todas las categorías de nuestro pensamiento y que llega aún a ponerse en oposición con ellas, algo "absolutamente heterogéneo" como denomina R. Otto a una de las características mas importante de lo "numinoso" (Lo Santo, Nadrid I93.5 p. 37). Citamos a continuación algunos textos al respecto: Kena Upanishad: "no llega ahí el ojo, no llega la voz ni la mente, no comprendemos, no imaginamos como alguien podría enseñarlo"; la Tejabindu Upanishad (7) declara expresamente que Brahman está "allende el dominio de la voz y de la mente"; Brihadaranyaka Upanishad. III, 8, II: "en verdad este inalterable, oh Garyi, es invisible y ve, inoible y oye, impensable y piensa, inconocible y conoce; solo él ve, solo él oye; solo él piensa, solo él conoce"; Kena Upanishads "es distinto de lo conocido y de lo desconocido"; Mundaka Upanishad: "es distinto del saber". A este carácter del Ser Supremo se refieren los Upanishads cuando califican $\mathrm{C}$ Braham de "difícil de ser visto", "inipensable", ơfitite'sno puede ser visto", "que no puede ser comprendido", "que no tiene nombre", "misterioso", "maravilloso". Dos observaciones mas completarán este aspecto: por un lado no existe para Brahman el mundo natural en que está ubicado el hombre; Brahman está allende la naturaleza que contemplan los ojos humanos y que forman para el hombre el horizonte en que se halla aprisionado; Mundaka Upanishad II, I4, "No brillan allí los relámpagos y menos aun nuestro fuego"; y en la Kaivalya Upanishad, 23 el Atman, al realizar su unión e identidad con Brahman, exclama: "Para mí no hay ni tierra, ni agua, ni fuego, para mí no hay ni éter ni firmamento" y por otro lado no se halla sujeto a los predicados de las cosas 
naturales; según la Brihadaranyaka Upanishad III, 8, 8, Brahman es "sin forma", "sin interior ni exterior", "sin medida". Hay que relacionar con este primer rasgo los medios de que se valen las Upanishads para describir a Brahman, característicos de toda la literatura mística: la oposición por contrarios, la descripción por negaciones y la acumulación de predicados; Icha Upanishad; "se mueve, no se mueve, está le jos, está cerca, dentro de todo, fuera de todo"; Brihadaranyaka Upanishad III, 8, 8; "aquel inalterable, oh Garyi, los brahmanes dicen que no es ni grueso ni fino, ni pequeño ni grande, sin sangre, sin grasa, sin sombra, sin obscuridad, sin viento, sin espacio, sin adhesión, sin sabor, sin olor, sin ojos, sin orejas, sin voz ni mente, sin luz, sin aliento, sin boca, sin medida, sin interior, sin exterior, no devora nada ni nada lo devora". No es necesario agregar después de lo anterior, que las Upanishads han dejado de lado la concepción antropomórfica de la diviniclad: bástenos citar al respecto a la Mundaka Upanishad que entre los predicados que atribuye al Ser Supremo cuenta con: "sin ojos, ni oidos", "sin manos ni pies", "sin respiración", "sin mente".

\section{PLENITUD DE BRAHMAN.}

Estas negaciones sin embargo no significan que lo único que el vidente ve en el objeto de la experiencia mística es algo negativo, un ente abstracto, un concepto vacío de contenido. Por el contrario el Ser Supremo de los Upanishads es plenitud, riqueza, abundancia, aunque tal plenitud es verdad que no puede ser expresada sino de manera inadecuada por el lenguaje. En las magníficas letanías que en muchos lugares elevan las Upanishads a Brahman se manifiesta este rasgo de su ausencia, sin importar que en ellas aparezca con frecuencia predicados negativos y aun incongruentes con el concepto y sentimiento que uno se puede formar de lo 
Absoluto. Cabe aquí recordar al respecto lo que dice Otto (ob. cit, p. 40) que a través de las mismas negaciones y contraposiciones se hace vivaz el sentimiento de las cualidades positivas del objeto mistico, pues la visión total y final que se forma es la de un ser. que supera y trasciende todo lo que abarca y conoce el hombre.

Citamos a continuación dos pasajes upanishádicos: Tejabindu. Upanishad 5-I I "aquello es lo supremo, misterioso, el sostén de todo, inmanifestado, Brahman que de nacla depende, cuya forma es lo limitado, atómico y sutil... desprovisto de forma, inmóvil, no implica la cluda, desprovisto de apoyo y substracto, el estado libre de contingencias, allende la voz y la mente...., la alegría, allende lo alegría, difícil de ser percibido, sin origen, inalterable, libre de emoción, eterno, firme, indestructible, es Brahman, es el Ser Supremo, el último límite, el supremo refugio"; Chandogya Ufamishad VII, I, 4: "es espíritu puro, cuyo cuerpo es la vida, cuya forma es la luz, cuyo concepto es la verdad, cuya esencia es el espacio, autor de todo, origen de todo, de todo olor, de todo gusto, que enyuelve todo, silencioso, indiferente". Esta plenitud de Brahnan también se revela en aquellos pasajes sobre los que luego tratarenos en "que aparecen a firmaciones de tinte panteista: Brahman lejos de ser nada es todo!

\section{BRAHILAN ES EL ARYHE.}

Mas aun el Sor Supremo es la última y suprema realidad en el sentido en oue Aristóteles interpretaba el arkhé cle los presocráticos: "dicen (los presocráticos) que el elemento constitutivo (stoikheion) y el arkhé es aquello por lo que están formados todos los seres y de lo que se producen, como de un origen, y en lo que terminan, como en un fin" (Metaphy A. 3). En efecto, el Ser Supremo, Brahman, es el origen 
de todo, todo ha salido de él, es aquello en que todo está establecido, es la esencia y sustancia de todo y es aquello en que todo termina, es, resumiendo, la realidad de la realidad" (satyasya satyam, Brihad aranyaka IJ, I, 20). Algunos textos corroborarán lo anterior: "acuello de lo cual estos seres han salido, aquelio en que viven cuando nacen y aquello en que entran cuando muercn, aquello es Brahman'" (Taitiriva Upamishad III, I ); "Como de un fuego encendido salen numerosas chispas de la misma esencia asi de lo inalterable, ol amigo, nacen los diversos seres y ahí mismo regresan" (Mundaka Upanishad II, I ); "en mi todo nace, en mi todo está establecido y en mi todo se disuelve" (Kaivalya Upanishad I 9$)$; "de él nace el aliento, la mente y todos los sentidos, el cielo, el viento, el rayo, las aguas y la tierra sostén de todo..., de él de diversos modos han nacido los dioses, los espíritus, los hombres, los animales, los pájaros, el aliento inspiratorio y el aliento expiratorio, el arroz y el trigo, la penitencia y la fé, la verdad, los noviciados, los ritos" (Mundaka Upanishad II, I) ; y la misma idea aparece en las magníficas parábolas de la Chandogya Upanishad (lectura VIII), que terminan todas con el refrán: "asi, oh amigo, tu no percibes al Ser y el Ser está ahí: por esa eséncia sutil, por ella todo está animado, ella es la realidad, ella es el Atman y tu eres eso, oh Chvetaketu".

\section{EL UNIVERSO.}

En los textos arriba citados tenemos cnfrentados por un lado a Brahman-Atman y por el otro el universo. En ellos no se niega la realidad de este aunque está indicada la idea que su realidad está subordinada a la Realiclad Suprema.

Como dice Oltremare (Histoire des idées Théosophiques dans l' Inde p. 9o): "está fuera de duda que cle uma manera general las Upanishads no han abandonado el pun- 
to de vista del realismo. Lejos de ahí, ellas se muestran tan fieles a las viejas ideas animistas que ellas afirman la realidad del mundo percibido en el sueño, como la del mundo percibido en el estado de vigilia".

Al lado de esta corriente sin duda la predominante en las Upanishads aparecen otras dos representadas por algunos textos y a la que algunos expositores de la filosofía upanishádica han dado el rango prevalente.

La una es la que hace del mundo una ilusión, una fantasmogoría maya el universo es ireal, producto del error del individuo que no conoce su identidad con Brahman y no sabe que fuera de este nada existe. Esta doctrina está tal vez expuesta en gérmen en algunos pasajes de la Brihadaranya Upanishad (II, 4, I4; IV, 3, 3I, donde se trasluce la duda de la existencia de una dualidad), de la Chandogya Upanishad (VI, , I, 3, donde se establece que todo es una mera modificación de la realidad verdadera), de la Katakha Upanishad (IV, Io. sq.) y es propugnada francamente en la Cvetacvatara Upanishad y entre los críticos occidentales Deissen la ha difundido y declarado la doctrina fundamentab de esos textos.

La otra corriente es la corriente panteista, corriente que Radhakrishnan (Indian Philosophy. I, p. 202-203) con sentido apologístico pretende negar, pero que evidentemente aparece en algunos lugares como en la Kaivaly'a Upamishad, 9: "él solo es todo lo que ha sido y será"; y sobre todo en la Chandogya Upanishad, III, I4, I: "todo lo que es, es Brahman". Pero si no es posible afirmar que el panteismo por decir así material (universo-Brahman) es una doctrina unánimemente profesado por las Upanishads, está fuera de duda que un panteismo por decir así espiritual es tesis general de esa literatura, como ya dijimos, y pronto al tratar del Atman volveremos a ocuparnos de ello con ma- 
yor atención: la identidad del Atman con Brahman es el principio básico y esencial no de una u otra sino de todas las Upanishads.

\section{CREACION DEL UNIVERSO}

Conviene que nos refiramos someramente aquí, aun a riesgo de romper la continuidad del tema, a dos cuestiones complementarias que se plantean al admitir la realidad del Universo: primeramente el problema de como fué creado el universo y en segundo lugar las relaciones de Brahman con el universo. Las Upanishads no indican en general de que manera fué creado el universo. Cuando lo hacen aluden por medio de imágenes a la creación por un proceso de emanación (cf. Mundaka Upanishad, I, I): "como una araña proyecta y retrae sus hilos, como las plantas brotan de la tierra, como los pelos y cabellos en el hombre, así de lo imperecedero nace este mundo" (y en la misma Upanishad II, I, citado mas arriba), sin indicar claramente si ello ocurre con o sin el consentimiento, con o sin la intervención activa y efectiva de Brahman. Algunas veces se refieren las Upanishadas a teorías mas complejas, divergentes entre sí, en que son evidentes los rezagos de la inspiración mítica predominantes en otras partes mas antiguas de la Literatura Vedica. Así la Chandogya Upanishad VI, I, 7 nos da una teoría cosmogónica en la que del. Ser original "solo y sin segundo" salen por el deseo expreso de este de "devenir múltiple", sucesiva y genealógicamente, el fuego, el agua, el alimento; luego el Ser penetrando en estos tres elementos y combinando a cada uno con los otros dos crea la multiplicidad de las cosas. La Brihadaranyaka Upanishad (I, 4) contiene otra teoría mas completa: el Atman en el origen se ve solo, se asusta de su soledad y deseoso de placer 
se divide en dos, en un par matrimonial, siguiendo a continuación, de modo genealógico y por medio de divisiones sucesivas en pares de componentes masculinos y femeninos, la creación de todos los seres existentes. La teoría de la Taittiriya Upanishad II, I es de carácter mas metafísico: establece la siguiente genealogía cósmica: del Atman nació el espacio, del espacio el viento, del viento el fuego, del fuego el agua, del agua la tierra, de la tierra el alimento, del alimento la semilla, de la semilla los hombres y todas las criaturas. Reminiscencias míticas, observaciones empiricas y fantasías filosóficas contribuyeron a la creación de estas teorías desde luego incongruentes con las doctrinas centrales de las Upanishads.

\section{GOBIERNO DEL UNIVERSO.}

En cuanto al segundo problema, el gobierno del universo, las mas de las veces no hay indicación de una intervención y acción directa de Brahman sobre el mundo, solo rara vez lo declaran las Upanishads el principio que actúa de modo directo sobre la vida cósmica y que establece la norma que la regula. "Así tenemos en la Brihadaranyaka Upanishad III, 8, 9: "por disposición de este imperecedero, oh Garya, el sol y la luna están separados, por disposición de este imperecedero los instantes, los momentos, los días y las noches, los medios meses, los meses, las estaciones, los años están separados; por disposición de este imperecedero, oh. Garya, corren unos ríos al oriente, otros al occidente, cada uno en su dirección partiendo de las montañas blancas".

\section{TEISMO EN BRAHIMAN.}

Finalmente en relación con ese segundo problema mencionaremos la introducción que tiene a veces lugar en la no- 
ción de Brahman de un elemento teístico. Esta introducción tiene lugar sobre todo en las Upanishads sectarias en que el teismo, en su forma de glorificación de un dios personal a quien uno se confía y de quien uno se siente dependiente. es un elemento predominante. Pero ya en Kathaka Upanishad II, 2.3 encontramos este elemento en la idea de que el conocimiento no sc obtiene con el aprendizaje sino que es revelado al hombre que es escogido por la suprema divinidad Brahman-Atman: "el Atman no puede ser alcanzado por medio del estudio o la inteligencia o de la mucha erudición; es alcanzado solo por aquel a quien el mismo Atman escoge; a este, el Atman revela su propia esencia". Lo mismo ocurre en la Cvetacvatara Upanishad y Mundaka Upanishad I, I, I, I,: "Brahman es el primero de los dioses, hacedor de todo, guardián del universo".

Estos rasgos de Brahman se completarán con aquellos del Atman de los que luego trataremos y que vista la identidad de ambos son propios del uno y del otro. Así tendremos desde dos puntos de vista la descripción de lo absoluto.

Pasamos por alto los diversos ensayos hechos por las Upanishads para definir la esencia de Brahman, consistentes en establecer una relación de identidad entre Brahman y ya un elemento material (la luna, el éter, el fuego, etc.), ya una función del hombre (o el soplo, el amor, el habla, etc.), ya conceptos abstractos (el ser, la alegría, etc.). Keith (the Religion and Philosophy of the Veda and Upanishads, Cambridge (Mass 1925 , p. $5^{16-522}$ ) enumera de modo muy completo esos diversos ensayos, "clara prueba de la fuerte actividad mental de ese período"-ensayos desde luego en contradicción con el carácter de heterogeneidad de Brahman $\mathrm{y}$ en su mayoria juzgados insuficientes aun por las propias Upanishads. 


\section{LA DOCTRINA DEL ATMAN.}

Frente al Ser Supremo o Brahman tenemos al alma individual o Atman, segundo término de la ecuación fundamental de las Upanishads: Brahman-Atman.

Lo mismo que con Brahman la existencia del Atman es un hecho al margen de toda discusión y que no necesita ser probado. Es su definición, su descripción lo que únicamente preocupa a los que compusieron estas obras.

Trataremos de acercar algo al lector a la icea de lo que es el Atman exponiendo primero la enseñanza de Prajapati a Indra, en seguida la teoría de los estados del Atman y finalmente enumerando las principales características del Atman.

\section{ENSEÑANZA DE PRAJAPATI.}

¿Qué es el Atman? tal es el difícil y complejo tema de la enseñanza que Prajapati, el creador, impartió a Indra que nos trasmite la Chandogya Upanishad (VIII, 7, I2). Prajapati empieza dando las características del Atman: "aquel Atman libre de malqute no está sometido a la vejez, ni a la muerte, ni al dolor, ni al hambre ola sed, cuyos deseos son realidad-hay que buscarlo, hay que desearlo conocer" (VIII, $7, x)$. Prajapati en primer lugar asimila el Atman a aquel hombre que aparece en un espejo o en un recipiente de agua-concepción materialista del Atman-: el Atman es el cuerpo. Pero Indra piensa que en ese caso el Atman seguiría el destino del cuerpo; estaría bien adornado cuando el cuerpo lo estaría, bien vestido cuando el cuerpo estuviese bien vestido, sería ciego cuando el cuerpo fuese ciego, paralítico cuando el cuerpo lo fuese y moriría con la muerte del cuerpo, e Indra agrega: "en ello no veo nada de consolador". Indra rechaza la primera solución tanto porque ella está en contrąicción con la definición que implícitamente da Praja- 
pati, en el comienzo, del Atman, cuanto porque no satisface su ansia de inmortalidad. En seguida Prajapati dice que el Atman es aquclla individualidad que se agita en sueños. Pero a Indra tampoco satisface esta solución: en este caso el Atman es cierto no sigue las variaciones del cuerpo como en la solución anterior "pero parece que ticne conciencia clcl dolor, parece que llora, en ello no encuentra nada de consolador" (VIII, IO, 2). Esa individualidad que sufre y llora, aunque el objeto de su pena es irreal, que se encucntra sometida al sufrimiento, aunque en realidad este para ella no existe, que está sometida a las experiencias de su vida antcrior, de su pasado sicológico, no puede ser el Atman que está allende del dolor, independiente, libre de todo, existente en sí y por sí. $\mathrm{Y}$ con esa solución cuan poco satisface Prajapati el anhelo humano de huir del mundo de sufrimientos y miseria en que yace encadenado el hombre. Por tercera vez da Prajapati una definición nueva del Atman: "cuando un hombre todo él dormido en una perfecta quietud no sueña-ese es el Atman-es la inmortalidad, es la felicidad, es Brahman" (VIII, 2, I ). Indra rehuye de esta concepción del alma porque comporta el aniquilaniento de la personalidad transformándolāen una abstracción, en una nada dotada de existencia, en un cnte formal carente de contenidoconcepción incapaz de llenar el ansia humana de propia, efectiva e integra perpetuidad. Prajapati expone al fin la verdadera teoría del Atman: "Maghavan (I), este cuerpo es mortal y sometido a la muerte. Este cuerpo es el recinto del Atman, inmortal, incorporal. Unido al cuerpo el Atman está sometido al placer y al dolor; libre del cuerpo puede librarse del placer y del dolor; cuando está libre del cuerpo ni el placer ni el dolor pueden afectarlo. El viento es incorpo-

(1) Indra. 


\section{$-218-$}

ral, la nube, el relámpago, el trueno son incorporales. Así como estos, yendo mas allá de esos espacios y acercándose a la luz suprema, aparecen cada uno en su verdadera forma, así el Atman saliendo de este cuerpo y accrcándose a la Luz Suprema aparece en su verdadera forma: es el espíritu Supremo" (VIII, I2, I, 3). La inmortalidad, la incorporeidad, el no estar afecto por sentimiento alguno de placer y de dolor, el recobrar su forma verdadera al salir del cuerpo y acercarse a la Luz Suprema (Brahman) y en fin su identidad con el espíritu Supremo-estos son los elementos que Prajapati en su última enseñanza da como rasgos del Atman.

\section{TEORIA DE LOS CUATRO ESTADOS.}

Trataremos de hacer mas clara la teoría del Atman, expuesta por Prajapati integrándola con la doctrina de los cuatro estados del Atman y con la descripción que de este hacen las Upanishads.

Según las Upanishads (cf. Mandukya Upanishad) el alma tiene cuatro estados o condiciones: el estado de vigilia, el estado del sueño, el estado del sueño profundo sin visiones y el estado llamado turiya, estado trascendental-estados que corresponden a las cuatro soluciones que sucesivamente propone Prajapati a Indra. En el estado de vigilia el alma está en contacto con el mundo material por medio de sus sentidos, el predominio del cuerpo es evidente: "con su ser engañado por la ignorancia, consagrándose al cuerpo, hace todo y se divicrte con los placeres variados de las mujeres, alimentos y bebidas" (Kaivalya Upanishad 12); "cuando percibe por medio de sus sentidos los objetos entonces es el estado de vigilia del Atman" (Sarva Upanishad I). El segundo estado, el estado del sueño con sueños comporta la creación por parte del sujeto de un mundo propio con los materiales que le suministra la memoria y que derivan de 
la experiencia de la vigilia, por lo que en cisrto modo el alma está en cierta medida bajo el influjo o dependencia del cuerpo: "en el sueño goza y sufre cn un mundo de existencia creado por su propia ignorancia” (Kaivaly'a Upanishad 13); "es cuando imprcgnado de recuerdos, percibe por medio de sus sentidos, en ausencia de objetos reales, objetos que solo son recucrdos inconcientes, entonces es el estado de sueño del Atman" (Sarza Upanishad I). El tercer estado es el del sueño profundo, el sueño sin visiones, no se da en él ninguna actividad por parte del sujeto; el alma es la absoluta vacuidad, está pura de las experiencias del estado de vigilia, libre de la influencia corporal y de los recuerdos subconcientes cel segundo cstado: es un estado negativo; "con la cesación de la actividad de los órganos y la ausencia de conocimiento diferenciado se da el estado susupti, el sueño profundo" (Sarz:a Upanishad I). En las Upanishads más antiguas, la Brihad Aranyaka y la Chandogya, el tercer estado del sueño profundo reprcsenta el estado mas alto; en esa vacuic.ad absoluta, en ese anonadamiento y sumersión absoluta en la nada por decir así divinizada se revcla la esencia verdadera del Atman y en ella tenía lugar la unión del alma individual con Branman. (cf. Gẹden, Hasting'sudEncyclopediapart. Upanishads).

Esta solución del aniquilamiento de la conciencia también es la de una serie de textos que no se refieren a la teoría de los estados del alma.

Citamos algunos pasajes al respecto a continuación: La Brihadaranyaka IV, 3, 2 I tiene una soberbia imagen: "como un hombre enlazado por la mujer amada no tiene conciencia de nada ni externo ni interno; así también el espiritu cnlazado por el Atman que conoce no tiene consciencia de nada ni externo ni interno; igualmente IV, 3, I9: "así como un águila o un gavilán después de errar por el es- 
pacio cansado, plegando a si stis alas se deja ir al su nido, así el espiritu corre a actuel estado donde dormido no dese a ningún deseo, no percibe ningún sueño". Radhakrishnan (Indian Philosophy I p. 240) concnta este texto diciendo: "es evidente que de un modo dificil de ser captado por nuestro intelecto el alma obtiene la liberación carente de tocla actividad, percepción, pensamiento o conciencia". La Chandogya Upanishad VIII, I5, 4 expresa las mismas idcas: "y la calma profunda (samprasada, calma profunda, sueño sin visiones) que se realiza al salir de este cuerpo y llegar a la Luz Suprcma es la inmortalidad, es la carencia de temor, es Brahman". Queremos recordar como conteniendo las mismas icleas las magnificas estrofas de $S_{n}$ Juan de la Cruz en su canción mística: "En anta noche oscura"

El aire de la almena
cuando ya sus cabellos esparcía
con su mano serena
en mi cuello hería
y todos mis sentidos suspendio
Quedéme yolvidéneetras
el rostro recliné isobre el Amado
cesó todo y dejéme
dejando mi cuidado
entre las azucenas olvidado.

Finalmente tenemos el cuarto estado, el qute mas dism cusiones suscita. ¿Por qué los viejos pensadores de las Upanishads incluycron en su teoría escolástica y derivada de los estados del alma un cuarto estado? ¿Es una construcción lógica y artificial o responde a alguna realidad? Ante todo si la unión con Brahman se realiza en el tercer estado y entraña el anonadamiento absoluto, el aniquilamiento total de la conciencia ¿cómo y cuándo el Atman percibe las cualidades 
sobrenaturales que determinan su esencia, el contenido riquísimo de su naturaleza, el sentimiento de la universaliclad de su verdadero ser-todo lo que se halla contenido en la descripción que nos dan las Upanishads del Atman y sobre la que luego trataremos?. La solución negativa está pues en contradicción con el aspecto positivo del Atman que dicha descripción nos suministra y por lo tanto los tres primeros estaclos no incluyen todos los aspectos de la vida del Atman. Esta observación justificaría la inclusión por motivos lógicos del cuarto estado. Además en toda la literatura mística nos encontraremos con dos aspectos de la experiencia sobrenatural: un aspecto negativo, como el expresado en las estrofas de San Juan de la Cruz; y un aspecto positivo como los contenidos en los numerosos textos citados por Otto en su obra citada y por William Janres en su obra The Varieties of Religions Experience, Edinburg (I9OI-IgO2).

Así pues, nos parece que este cuarto estado responde a una realidad de la experiencia mística-el estado del éxtasis.

Este cuarto estado dice Oltremare (L' Histoire des idées theosophiqucs dans I' Inde, P. I25, Paríc I906) "es aquel en que „Brahman ya no está unificado, no es inteligente, no es no-inteligente, es invisible, escapa a toda demostración, trasciende todo pensamiento y no admite ninguna definición, la única prueba en lo que le concierne es la fé en el alma; es sin cambio, feliz, sin dualidad", es un estado positivo, trascendente y heterogéneo.

Las características del Atman, sobre las que a continuación tratamos, nos darán una idea de este cuarto estado.

Dada la identidad esencial de Brahman y de Atman es natural que los rasgos distintivos del uno y del otro sean los mismos y que los del uno aclaren e integren la imagen del otro y recíprocamente-lo cual excusará las repeticiones en que incurramos. 


\section{HETEROGENEIDAD DEL ATMAN.}

Ante todo mencionaremos la heterogencidad del Atman: es un objeto que trasciende y derrota la mente humana. En muchos textos se halla expresada csta idea: cf. Kathaka Upannishad I, 22: "el Atman no puede ser alcanzada por medio del estudio o de la inteligencia o de mucha erudición"; Brihadaranyaka Upanishad III, 4, 7 : "no podrías ver al que ve la visión, no podrías oir al que oye la audición, no podrías pensar al que piensa el pensamiento, no podrías conocer al que conoce el conocimiento; invisible y ve, inoible y oye, impensable y piensa, inconocible y conoce: solo $\mathrm{El}$ ve, solo El oye, solo El piensa, solo El conoce".

Las Upanishads además emplean refiriéndose al Atman los mismos términos que vimos empleados respecto a Brahman para indicar que este no puede ser pensado ni expresado y también recurren a los dos medios característicos de descripción: la oposición de contrarios y la acumulación de negaciones. Respecto a este último medio queremos agregar que la Brihadaranyaka IV, 2, 4y IV, 4, 21 declara expresamente que el Atman es neti, neti, no, no, es decir que para definirlo es preciso emplear negaciones y diferenciarlo de todo auello que el hombre percibe en sus experiencias naturales.

\section{PLENITUD DEL ATMAaN.}

Este rasgo no obsta sin embargo para que las Upanishads den algunas características positivas del Atman. Primeramente una amplísima conciencia de si mismo, el sentimiento de una personalidad cósmica, de la universalidad de su esencia; parece que el Atman encadenado hasta entonces por el cuerpo y el error rompiese de repente sus barreras y 
desbordase e inundase por todo lo existente. Las Upanishads recurren a imágenes y analogías para la expresión de este sentimiento. "Tan vasto como el espacio, es este espacio, el interior del corazón; en él la tierra y el cielo están reunidos, el fuego y el viento, el sol y la luna, el relámpago y las estrellas, lo que es de cada uno en este mundo y lo que no es-todo en él está reunido" (Chandogya Upanishad VIII, I, 3): "este Atman que hay en el interior de mi corazón... es mas grande que la tierra, mas grande que el espacio, mas grande que el cielo, mas grande que los mundos" (ibid. III, I4, 3).

\section{ATMAN ES EL ARKHE.}

Así como Brahman es declarado fundamento, origen y fin del universo así también lo es el Atman: "quien ve a todos los seres en el Atman y al Atman en todos los seres aquel ya no duda" ( Iça 6) ; "en mi todo nace, en mi todo está establecido, en mi todo se disuelve" (Kaivalya Upanishad I9); "como de un fuego brillante salen chispas hacia todo lado, así de este Atman salen las fuerzas vitales (praña), de las fuerzas vitales los dioses, de los dioses los mundos" (Kausitaki Upanishad III, 2).

La Brihadaranyaka II, 7, 3, 23 dice: "aquel que estando en la tierra es diferente de la tierra, a quien la tierra no conoce y de quien la tierra es el cuerpo y quien estando en el interior de la tierra la gobierna-ese es tu Atman, moderador interno, inmortal" y luego monótonamente afirma lo mismo de todo en el "orden de los dioses" y en el orden de los seres". "Aquel del cual surge el año con sus días, a aquel los dioses lo adoran como la luz de las luces, como la vida inmortal. Aquel en que están establecidos los seres y el espacio, aquel lo considero el Atman inmortal, yo sabio, yo que soy el Brahman inmortal" (Brihadaranyaka Upanishad 
IV, 4, I6, I7) ; "para aquel que piensa así, que sabe así, que ve así, para aquel la vida procede del Atman, del Atman procede la esperanza, del Atman la memoria, del Atman el espacio, del Atman el vigor, del Atman las aguas, del Atman lo visible y lo invisible, del Atman el alimento, del Atman la fuerza, del Atman el pensamiento, del Atman la reflexión, del Atman la mente, del Atman la voz, del Atman las palabras, del Atman las formas sagradas, del Atman los actos rituales-del Atman procede todo". (Chandogya Upanishad VII, 26, I).

Del mismo modo se declara la identidad panteística del universo con el Atman: "yo soy todo lo que existe" (Brihadaranyaka Upanishad IV, 3, 20). Y también es declarado señor de todo: cf. Brihadaranyaka Upanishad IV, 4, $2 \mathrm{I}$.

\section{DESAPARICION DE TODA DUALIDAD.}

Además toda duaídad desaparece; la distinción entre objeto y sujeto, entre yo y aquello, entre lo interior y lo exterior deja de darse. (Brihadaranyaka Upanishad IV, 3, 23, 30). El hombre como dicelal Brihadaranyaka Upanishad IV, 4, 2: "se ha vuelto uno (ekibhavanti). Como los ríos en el océano, como los jugos de las flores en la miel que elaboran las abejas (Chandogya Upanishad IVI, 6, 9, IO) así todo se ha refundido en una sola unidad espiritual (Sarva ekibhavanti, Mundaka Upanishadd III, 2). "No hay aquí diversidad alguna; de la muerte pasa a la muerte quien aquí ve diversidad" (Brihadaranyaka Upanishad IV, 4, I9). Y en esta unidad las funciones sensoriales mentales de percepción no pueden ya tener lugar: "cuando se da dualidad, lo uno ve a lo otro, lo uno siente a lo otro, lo uno gusta a lo otro, lo uno habla con lo otro, lo uno oye a lo otro, lo uno piensa en lo otro, lo uno percibe a lo otro, lo uno conoce a lo otro; 
pero donde todo es Atman ¿ por medio de que y a quien vería, por medio de que y a quien sentiría, por medio de que y a quien gustaría, por medio de que y a quien hablaría, por medio de que y a quien oiría, por medio de que y a quien pensaría, por medio de que y a quien percibiría, por medio de que y a quien conocería?" (Brihadaranyaka Upanishad IV, 5, I 5). Nos parece que cuando las Upanishads hablan de la unidad (Ekatvan) que "contempla", mejor dicho: "vive", el vidente, no se debe interpretar en el sentido de una unidad filosófica, matemática como aquella a que llegan Parmenides y Platón, se trata mas bien de una unificación o refundición en un solo ser de todos los seres individuales, de una unidad concreta por decir así y no abstracta, producto de un sentimiento panteístico y místico y no de una especulacion abstractizante de la mente. Por otro lado el Atman al recobar su esencia está allende las distinciones del mundo; ha superado lo relativo y ha entrado en la esfera de lo absoluto, mas allá de los valores morales, sociales y religiosos que ha establecido el hombre. "Entonces el padre ya no es padre, la madre ya no es madre, los mundos ya no son mundos, los dioses ya no son dioses, los vedas ya no son yedas; ahí el ladrón ya no es ladrón, el abortador ya no es abortador, el çandala ya no es el çandala, el paulkasa ya no es paulkasa, el monje mendigo ya no es monje mendigo, el asceta ya no es asceta" (Brihadaranyaka IV, 3,22 ). "Entonces lejos de él: he hecho bien, he hecho mal, pues está allende de ambos; ya lo hecho y lo no hecho no lo atormentan" (ibid, 4, 2I) "Allende del mal y del bien" (Kathaka Upanishad II, I4).

\section{OTRAS CARACTERISTICAS.}

Otra serie de epítetos aluden a un carácter del Atman, también muy importante, de firmeza, indestructibiliclad, inal- 
terabilidad, inmortalidad. En el capítulo segundo de la Bhagavad-Gita encontrará el lector un hermoso desarrollo de este concepto de las Upanishad. Aquí solo mencionaremos algunos trozos: Brihadarranyaka Upanishad IV, 2, 4 "este Atman es $10, n o$; es incogible pues no puede ser cogido, indestructible pues no puede ser destruido, sin adherencia pues no está adherido, no ligado, no vacila, no perece". Ibiden IV, 4, 20: "El Atman puro, allende el espacio, sin nacimiento, grande, firme". Ibidem 24: "Sin muerte, inmortal, sin temor".

\section{ATMAN ES LA ALEGRIA.}

$Y$ a base de todo esto un sentimiento de goce $y$ deleite frente al que el placer y la alegría de este mundo es una vana sombra. La felicidad de Brahman dice la Brihadaranyaka Upanishad $V, \mathrm{I} 3,33$ sq. es cientos de cientos de veces superior a la felicidad humana. La Chandogya Upanishad VII, 2I, I dice: "solo hay alegría en la infinitud, en lo finito no hay alegría; la infinidad es la alegría" y luego aclara que entiencle por infinitud y por finito "cuando no se ve a otra cosa, cuando no se oye a otra cosa, cuando no se percibe a otra cosa - esa es la infinidad-cuando se ve a otra cosa, cuando se oye a otra cosa cuando se percibe a otra cosa-es lo finito. La infinidad es lo inmortal, lo finito es lo mortal" (ibid. 24). "Es su (del Atman) supremo fin, es su supremo estado, es su supremo mundo, es su suprema felicidad; los otros seres viven de una partícula de esta felicidad (Brihadaranyaka Upanishad III, 4, 2; III, 5, I ; III, 7, 23).

"El Atman no está sujeto al hambre o a la sed, ni al dolor ni al error, a la vejez o a muerte (Brihadaranyaka Upanishad III, 5, I). "La forma libre de dolor y miedo" (Brihadaranyaka Upanishad IV, 3, 2I) "Entonces ha atra- 
vesado todos los males del corazón". Otto (obra citada" p. 47 , 6r ) da como uno de los elementos del objeto de la experiencia mística el aspecto fascinante del numen que se traduce en el vidente por una conmoción exaltada e inexpresable de alegría. Este sentimiento de goce se manifiesta en las experiencias de místicos de las mas diversas religiones; queremos solo citar a Santa Rosa de Lima que al ser interrogada sobre los efectos de "la presencia de la divinidad", declaró que estos eran "afectos tiernos de amor, un firme y dulce gozo sobre todos los gozos imaginables" (Juan Meléndez: Tesoros verdaderos de las Indias, Bibl. de Cultura Peruana; primera serie, número 7 " los Místicos p. I42).

En algunas Upanishads se dice de Brahman que es ananda, el deleite o alegría y la Taittiriya Upanishad después de una extensa investigación identifica a Brahman con Ananda (Alegría). A base de este texto Radhalkrishnan (Indian Philosophy I p. I63 sq.) define la Realidad Suprema como Ananda. Pero esto nos parece un evidente error, primeramente porque contradice la aseveración frecuente de los Upanishads de que lo absoluto es indefinible y además porque en este caso tanto las Upanishads como Radhakrishnan identifican a Brahman como uno de los elementos del estado subjetivo experimentado por el vidente a consecuencia de la unión mística; el místico se siente henchido de gozo y alegría y con la incoherncia propia de su manera de expresarse afirma que Brahman es la alegría como podría serlo otro de los elementos de su experiencia.

\section{IDENTIDAD DE BRAHMAN Y ATMAN.}

Finalmente el rasgo mas importante del Atman es el expresado en la fórmula ya conocida: Atman-Brahman, principio básico de las Upanishad y que da a esa extensa 
masa de textos de diversas épocas y autores distintos, unidad y coherencia: "yo soy Brahman" (Brihadaranyaka Upanishad I, 4, Io) "lo que tu eres eso yo soy" le dice el Atman a Brahman en el Kausitaki Upanishad I, 5, sq., fórmula que a cada paso es encontrada en los textos upanishádicos. En cuanto a la naturaleza de esta unión nos referimos a lo dicho al tratar de la teoría de los cuatro estados del Atman.

\section{PESIMISMO.}

La naturaleza de Brahman, de Atman y la identidad y unidad de ambos, son los temas esenciales de las Upanishads, pero al lado de ellos ocurren ciros de menos importancia que pasamos a tratar de manera somera. La naturaleza de la India enervadora y exasperante, las condiciones sociales y económicas con su pobreza y su miseria establecidas y tal vez también la influencia de las poblaciones indígenas sometidas por los invasores indoeuropeos son consideradas como las causas principales del pesimismo doloroso característico del espíritu hindú (cf. H. D. Griswold, Hasting s Encyclop, art. Pessimism). Este pesimismo es característico de las Upanishad y es uno de" los rasgos que los distinguen de la literatura anterior envuelta en una atmósfera de marcado optimismo en su concepción del mundo y de la vida. La vida es transitoria y sometida al dolor y el cuerpo es repugnante-tal es la forma que reviste el pesimismo en estos textos (cf. Maitrayana Upanishad I, 3, sq.; Brihadaranyaka Upanishad III, I, 3; II, IO; IV, 3, 7; IV, 2; Kathaka Upanishad I, I6).

Al lado de este sentimiento de lo transitorio y pasajero del hombre y del mundo descubrimos a veces una ansia de inmortalidad, un deseo de descubrir un destino mejor y de salir de la duda al respecto, tan dolorosa como las limitaciones 
a que está sujeto el hombre. Así recordamos el diálogo entre Prajapati e Indra con su trágico sentido y las afanosas interrogaciones de Naciketas a la Muerte para que le revele la verdad (en el Kathaka Upanishad); a través de estos pasajes vislumbramos la intensa inquietud espiritual que debió reinar en esa época.

\section{IA TEORIA DEL SAMSARA.}

Paralela a la concepción pesimista y contribuyendo a fortalecerla tenemos la idea del samsara, de las trasmigraciones, del círculo cerrado de nacimientos y muertes sucesivas a que está encadenado de modo necesario el hombre.

Esta teoría no figura ni en los Vedas ni en los Brahmanas, excepto en el Catapatha Brahmana, obra por lo demás relativamente reciente e influenciado por las Upanishad, aunque si hay elementos favorables a su eclosión.

La doctrina de la trasmigración no necesita pruebas en la India, es por sí algo indiscutible que se impone como un dogma inconmovible at la concienciat de todo aquel que piensa. El origen dēesta creencial hay que remontarla, como se sabe, a las creencias comunes, a pueblos primitivos: de que el alma del hombre al morir se reencarna en plantas y animales, de que la concepción consiste en la "bajada" en el cuerpo de un ser desencarnado, antiguo hombre o animal, y de que el padre se reencarna en su hijo-creencia esta basada en parte en la semejanza corriente del uno en el otro, consideración esta que adquiere mayor fuerza si se toma en cuenta que todas las almas son originariamente idénticas a Brahman y entre sí-a lo que hay que agregar la idea que sin una existencia anterior, en que uno ha acumulado méritos y deméritos, serían inexplicables tanto las desgracias o felicidades que contra razón y sin causa experimenta uno 
en la vida, como las desigualdades de los seres. Citamos algunos textos upanishádicos en que se refiere a esta teoría: "como el trigo, perece el hombre, como el trigo vuelve a renacer" (Kathaka Upanishad I, 8); "ojalá nunca vuelva al seno maternal, brillante, que devora sin dientes (?) ojalá nunca vuelva" (Chandogya Upanishad VII, I4); "como una oruga llegada a la extremidad de una hoja se desliza hacia otra hoja, así el alma liberándose del cuerpo y de la ignorancia pasa a otro cuerpo (Brihadaranyaka Upanishad IV, 4, 3).

A veces entrelazada con la idea del samsara aparecen otros motivos de menor importancia en la economía general de la doctrina. Por un lado un motivo de orden moral: la forma de las reencarnaciones depende de la conducta del hombre en su vida anterior. "aquellos que tienen una conducta satisfactoria tienen la perspectiva de tener un nacimiento satisfactorio: Brahman, guerrero, mercader. Aquellos por el contrario que tienen una conducta impura tienen la perspectiva de un nacimiento impuro: perro, puerco, paria" (Chandogya Upanishad $\Phi$, ro, z). Por otro lado un motivo constituído por rezagos de creencias anteriores al parecer de orden mítico: después de la muerte hay dos caminos : el camino de los dioses reservado a los que practican la fé y el ascetismo, a través de la llama, de los días claros del mes, de los meses claros del año, del sol. de la luna, del rayo hasta llegar donde Brahman-y el camino de los difuntos para el resto de las gentes, a través del humo de la noche, de los días oscuros, del mes, de los meses oscuros del año, del mundo de los difuntos, del espacio hasta la luna, donde permanecen mas o menos tiempo para regresar después por el mismo camino a reencarnarse de nuevo (Chandogy'a Upanishad V, Io, 3, 6, cf. Brihadaranyaka Upanishad VI, 2, 2). 
En cuanto a la causa eficiente dei samsara está constituida por el deseo: el que tiene deseos se reencarna y no llega donde Brahman. En cuanto al concepto de Karman, que tanto prosperaría ulteriormente y que es una ctapa mas avanzada de la especulación alrededor de la creencia a las trasmigraciones, no tiene este en las Upanishads antiguas un rasgo preminente. Cf. "quien tiene deseos, esc se reencarna aqui y allá" (Mundaka Upanishad III, 2); "aquel que no tiene dcseos, carente de deseos, que ha obtenido su desco, cuya Atman es su ceseo, de aquel los soplos vitalcs no se escapan $y$ siendo Brahman llega donde Brahmann... cuando desaparecen todos los deseos que surgen en el corazón, entonces de morlal se vuelve inmortal y alcanza a Brahman ( $B r^{-}{ }^{-}$ hadaranyaka Upanishad IV, $3,6,7)$.

\section{LA LIBERACION.}

Por último, coronación de toda la doctrina tenemos el concepto de la liberación, problema capital del pensaniento hinclú. Las Upanishads no constituyen tura filosofía en el sentido occidental del térnino sino mas bien tura religión, un modo de vivir, su finalidad no es la ciencia pura, sino la liberación del dolor, del, sufrimiento y de la muerte por la entrada en una esfera supernatural y su método no es especulativo sino disciplinario. La liberación comporta dos elementos: un elemento negativo y un elemento positivo. Pues por un lado constituye la liberación del dolor y por el otro la entrada en un dominio de felicidad absoluta; contiene la destrucción de to humano y relativo que envurelve el Atman para libcrar a lo divino y absoluto que es el hombre en el fondo de sti esencia: la derrota de lo mortal y la victoria de lo inmortal. 


\section{$-232-$}

La liberación consiste en la unión mística con Brahnman y por lo tanto en la liberación de las cadenas de la reencarnación. Esta es la doctrina general de las Upanịshads; sin embargo este concepto es a veces oscurecido por la iclea de que la liberación consiste en la inmortaliclad y en la entrada en un mundo de recompensa rezagos de las ideas tésticas que dominarian después (Keith ob. cit. p. 582 ).

Fernando tola Mendoza. 